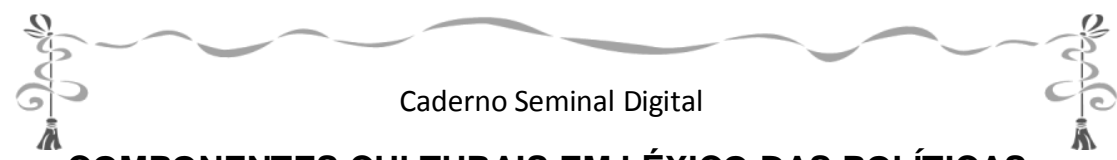

\title{
COMPONENTES CULTURAIS EM LÉXICO DAS POLÍTICAS
} PÚBLICAS

CULTURAL COMPONENTS IN LEXICO OF PUBLIC POLICES

\section{Eliana Meneses de MELO (UMC/GRUPPU ${ }^{3}$ )}

Resumo: Avalia as relações axiológicas frente aos componentes discursivos que envolvem políticas públicas. Avalia as concepções sociais manifestadas em expressões voltadas à inclusão social. 0 estudo foi realizado a partir de corpus constituído por textos jornalísticos em diálogo com a temática políticas públicas. A análise teve como eixo condutor os componentes estáticos e dinâmicos dos traços de sentido.

Palavras-chave: Discursos, Semiótica, Políticas Públicas, Dignidade Humana.

Abstract: Evaluates relationships axiological against discursive components involving public policy. Assesses the social conceptions expressed in expressions aimed at social inclusion. The study was conducted from corpus consisting of newspaper texts in dialogue with the public policy issue. The analysis was conductor axis components of the static and dynamic features of meaning.

Keywords: Speeches, Semiotics, Public Policy, Human Dignity.

33emelo@uol.com.br

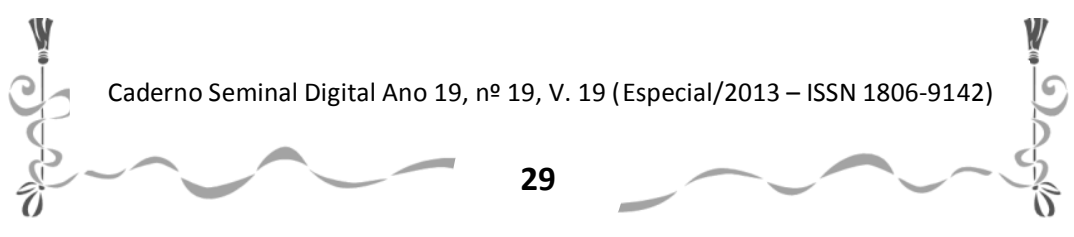




\section{APRESENTAÇÃO}

Tendo como objeto de interesse as linguagens sobre as quais se manifestam os agentes dos diferentes segmentos culturais e sociais, este estudo foi concebido a partir das problemáticas sobre as quais se edificam os discursos que manifestam políticas públicas. A concepção inicial para nortear o percurso de pesquisa teve como entendimento que políticas públicas devem ser configuradas como um universo de discurso com características diferentes do que classicamente se define como discurso político.

De maneira geral, próprio do discurso político esta a retórica, os elementos de persuasão cuja intencionalidade se inscreve no "levar o outro a um querer". Um poder que se manifesta no campo do sujeito institucionalizado ou que queira se legitimar a partir da adesão de outro sujeito. No caso da concepção de políticas públicas como discurso o que se sobrepõem são as estratégicas e as operações que expressem decisões políticas. Neste caso, é perceptível um "propor-ação: um fazer". O sujeito, em conformidade com o contexto, já não visa a sedução e sim a eficácia em dar materialidade às demandas sociais.

Secchi (2010), estabelecendo diferenças entre os termos políticas e políticas públicas, afirma que políticas públicas tratam do conteúdo concreto e do conteúdo simbólico de decisões políticas, e do processo e atuação dessas decisões. É justamente a existência de um conteúdo simbólico que

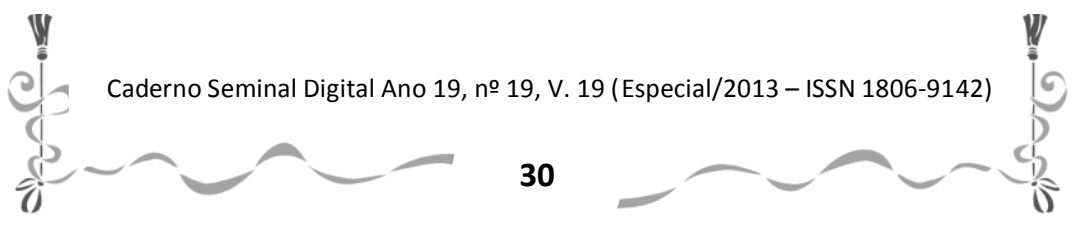


torna possível a tipificação de políticas públicas como um universo de discurso e não um apêndice do discurso político. Ainda em conformidade de Secchi:

Uma política pública é uma orientação à atividade ou à passividade de alguém; as atividades ou passividades decorrentes dessa orientação também fazem parte da política pública; uma política possui dois elementos fundamentais: intencionalidade pública e resposta a um problema público, em outras palavras, a razão para o estabelecimento de uma política pública é o tratamento ou a resolução de um problema entendido como coletivamente relevante (SECCHI: 2010, p. 2).

Em diálogo com a definição apresentada, $a$ intencionalidade pública e resposta a um problema público pressupõem a realização de leitura das diferentes dimensões sociais, troca simbólica entre os agentes. Elas emergem da criação, planejamento e materialidade no fazer, tudo em conformidade com a visão de mundo dos agentes. Trata-se de um discurso marcado pela interdiscursividade e por uma base axiológica variável na medida em que se sustenta e alimenta uma semiótica hibrida, complexa.

Nota-se que, neste contexto, a linguagem verbal conduz projetos, discussões e uma série de produções discursivas por onde se faz a circulação das problemáticas sociais bem como das diferentes posturas dos vários atores de tal forma que a palavra sinaliza o patrimônio cultural das forças atuantes nos discursos, quer seja na configuração

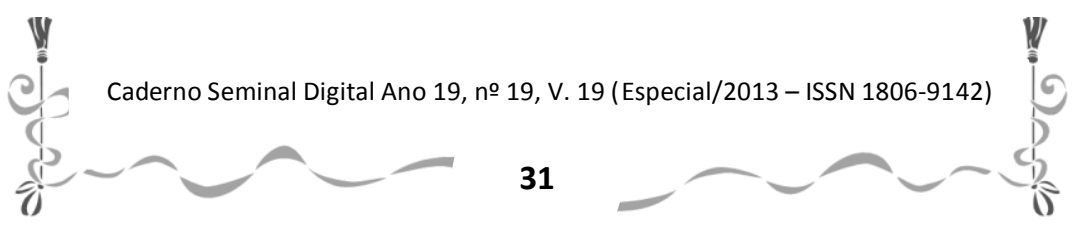


Caderno Seminal Digital

isolado do universo vocabular, quer seja na dinâmica contextual das palavras.

Outro procedimento foi delimitar o eixo temático, uma vez que as demandas sociais, nutrientes das políticas públicas, são originárias de várias áreas, saúde, educação, moradia, segurança, transporte, entre outras. Escolheu-se aspectos dos discursos das políticas públicas que se criam e se manifestam a partir das dimensões urbanas e que refletem as desigualdades sociais e as relações contraditórias da tolerância e inclusão social, especificamente o seguimento adjetivado como 'população de rua'

Em que medida o léxico destinado ao morador de rua recebe e reflete signos da interdiscursividade social? Em termos concepção espacial, a rua é lugar de trânsito dos sujeitos da cidadania estabelecida, ao mesmo tempo é o espaço que contempla o discurso dos sujeitos em situação de rua para os quais o espaço destinado ao transitar se configura como habitação.

Para material de análise elegeu-se dois seguimentos: matérias jornalísticas publicadas pela Folha de S. Paulo, em fevereiro de 2012, e a discussão proposta no documento Política Nacional para a Inclusão Social da População em Situação de Rua - Governo Federal: 2008. Reside na heterogeneidade e nos componentes semânticos da cultura para inclusão o fio condutor da pesquisa.

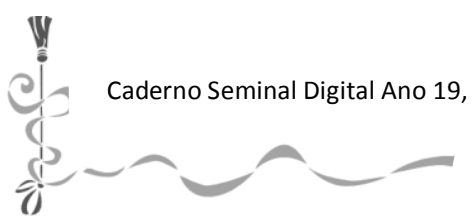

32
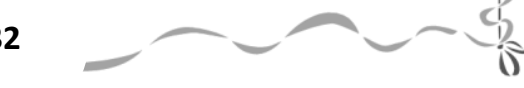
Caderno Seminal Digital

Os discursos das Políticas Públicas respaldados na oficialidade política e social de suas mediações refletem valores culturais para o cotidiano das vivências da cidadania no tocante à inclusão social? $\mathrm{Na}$ concepção de leitura e análise, o discurso jornalístico assume o papel de narrador do cotidiano, o discurso das políticas públicas como manifestação legítima da busca da justiça social e cidadania e qualidade de vida.

O percurso teórico escolhido para o estudo se fundamenta na Interdisciplinaridade, na semiótica, nos estudos do léxico e nos estudos voltados aos discursos sociais.

\section{I - DO LÉXICO AO DISCURSO}

Inequívoco é o elo entre léxico é cultura. Por diferentes trajetórias, o século $X X$ trouxe a tona muitas reflexões e bases conceituais que apontaram para este elo que, nos tempos contemporâneos já se tornaram clássicos. Apenas em caráter exemplificativos, cita-se os trabalhos de Sapir, Whorf, Pottier, Harris, Benveniste, entre outros.

Pensar o léxico na dimensão social e cultural da língua significa, em primeira instância, ter em mente o trabalho coletivo que está presente no léxico de qualquer realidade linguística. Fruto da criação social, o léxico é uma propriedade da comunidade que, através dele, cria recria e atualiza valores, manifestando-os no conjunto de suas múltiplas produções discursivas.

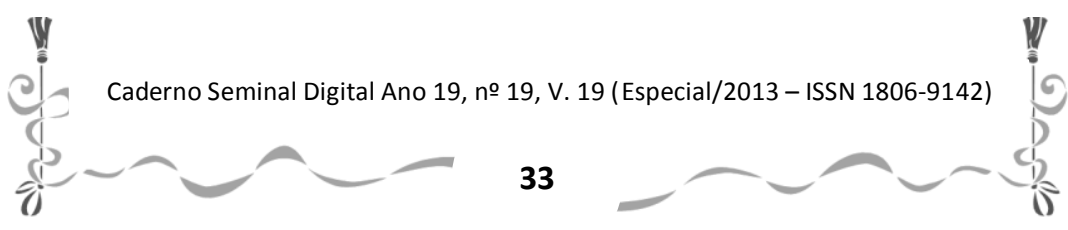


Maria Aparecida Barbosa (1978), em sintonia com o trabalho de C. Teodoro Pais, o homem só conhece o universo natural através dos códigos por ele mesmo estruturados. Tendo como referência esses sistemas de significação, a sociedade humana cria outro universo que passa a ser a base do que entende por mundo real. Ação de criação se modela em conformidade com a semiótica natural. O processo faz chegar ao universo referencial, antropocultural, primeiro nível da semiótica humana:

Nessa diversidade de visões de mundo, nessas diferentes estruturas semiológicas, há uma constante; o processo de que se servem as diferentes culturas para a elaboração de seus códigos e para a estruturação de seus universos, processos que podem se analisados na mesma metalinguagem. (BARBOSA: 1978, p.22)

Nestes termos, os dados contidos em um universo antropocultural são tratados por sistemas de significação criados pelo homem e apenas neles é que podem se esgotar. Sendo assim, o que se vivencia em termos da história da humanidade é a ampliação dos universos de linguagem, dos sistemas por onde circulam, pluralidade de sentidos e diversidades culturais. O léxico passeia por entre os múltiplos discursos sociais e estéticos remotivado, expressando novos traços de sentido.

Assim sendo, os trabalhos sobre linguagem e os múltiplos discursos demandaram reflexões em torno de questões relacionadas às dinâmicas das produções discursos

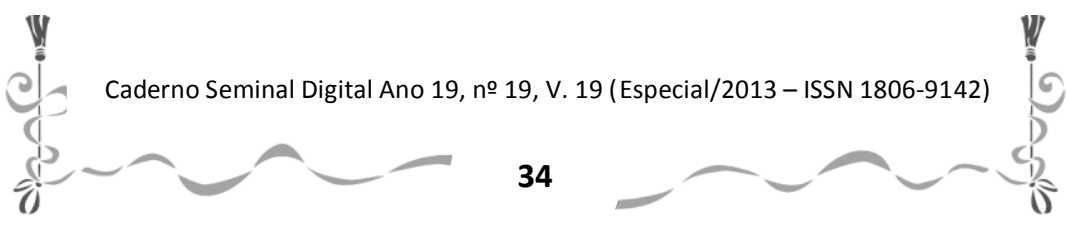


na emanação do percurso semiótico para além da produção do sentido. A significação é a referência a uma dada realidade, na dialética entre o olhar e sentir da comunidade criadora. É através de articulações interna e externa aos diferentes textos que se apreende o sentido possível.

O sentido produzido nas comunicações está envolto à sintaxe pela qual circulam atores de um discurso no contexto da enunciação. Esses sujeitos trazem aos cenários discursivos a memória das experiências vivenciadas, revestidas dos traços de cultura. Elas aparecem nas dinâmicas da linguagem através do encadeamento de certos elementos que na enunciação expressam marcas de espaço, tempo e dos sujeitos que se situam na enunciação. Cada discurso contém determinantes para a sua leitura, diretamente implicados aos seus estatutos discursivos e ao conjunto de signos em torno dos quais se constituem.

Quando se mergulha nas dimensões dos signos, símbolos e nas diferentes linguagens, encontra-se uma gama enorme de percursos revestidos por signos em múltiplas significações. São as linguagens em criação e recriação a percorrerem os espaços do contraditório. Verbo e imagens se associam em torno de suas variadas formas de expressão, fato que permite lembrar-se da interdisciplinaridade, sempre presente nos atos investigativos sobre os discursos, produção e circulação de sentidos.
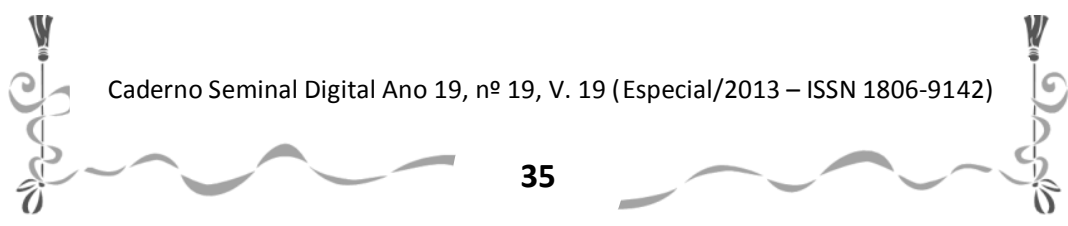
Caderno Seminal Digital

Discursos são espaços importantes para o pesquisador quando este nutre seus interesses investigativos nas confluências das práticas sociais. As linguagens expressas na comunicação humana das práticas cotidianas são elaboradas por marcas de diversidades em signos e símbolos, compondo significações. Dos recortes poéticos que alimentam sentidos e almas, às produções das ciências e tecnologias, linguagens expressam as narrativas criadas, reinventadas, materializando objetos, formas e os contraditórios da vivencia civilizatória humana.

Percursos espessos em variedade de conteúdos, os discursos sociais são aberturas para as realidades de diferentes modos da vida humana. Reflexo e reflexões de diálogos e de suas vozes, por eles ecoam objetividades e subjetividades do ser em vida que se lança, que se perde e que se edifica. Tensões, confrontos e conflitos a serem lidos, analisados, desmanchados pelo pesquisador. Talvez seja por estes fatores que os trabalhos investigativos sobre os discursos sempre apontarem para as trilhas da produção do conhecimento instigando ações interdisciplinaridade.

A tradição dos estudos linguísticos e das linguagens humanas, ainda que focadas em um único recorte, sempre assinalam nos seus resultados a existência do outro. Tome-se, por exemplo, estudo descritivo dos componentes linguísticos: os sons vistos pelos pontos de articulação, pelos variantes

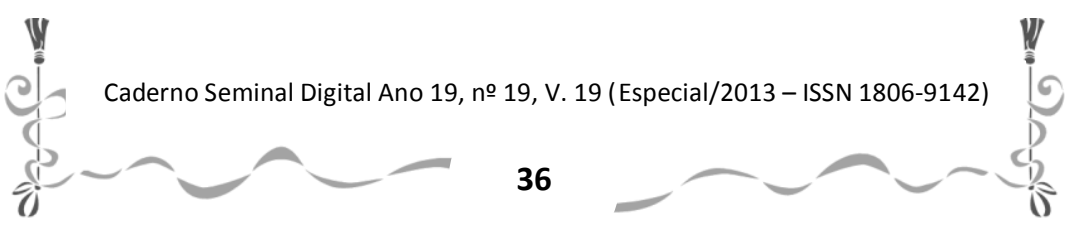


Caderno Seminal Digital

住

socioculturais, pelas interferências acústicas, pelos traços de sentido e contexto de ocorrência, entre outros.

Ter como intencionalidade de pesquisa as emanações discursivas, os caminhos advindos das várias correntes investigativas são entremeados pela pluralidade de conceitos que se tornam ferramentas destinadas a desvendar as redes de significações pelas quais se concretizam os diálogos de diferentes discursos, bem como os que são gerados nas relações de heterogeneidade cultural e nas leituras revelam a pluralidade cultural dos sujeitos.

Assim, conceber o mundo em termos de configuração semiótica, pressupõe existência plural de discursos recortados e interligados pela ação das diferentes experiências e dos atores que dão forma aos discursos sociais em sistemas abertos e dinâmicos, sempre gerando novos sentidos e possíveis interpretações. Elas atualizam e mantém os processos dinâmicos criados no próprio âmbito das múltiplas vivências sociais (MELO, 2008, p.13)

A rede de sentidos que forma a base deste trabalho advém de emanações discursivas do Poder e de poder. Tratase, nos termos propostos por Foucault, de trama semântica construída das tensões entre micro e macro estruturas. Sobre os sistemas semióticos, as tensões estão presentes em discursos verbais, afloradas na escolha lexical e discursos presentes na rua (espaço de trânsito de signos) (FOUCAULT, 2000, p. 1966).

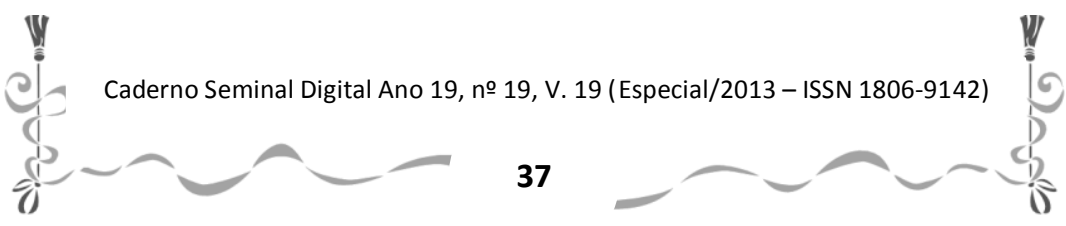


Caderno Seminal Digital

Todo sistema semiótico é constituído por diversidade de significações, seu funcionamento está pautado pelo princípio de ordem desigual. Ele convoca outros sistemas e seus subsistemas, (FONSECA, 2003 p, 261). As mensagens que em um sistema se vasam representam a resultante de uma mais ou menos forte interação que se trava entre ele e os outros sistemas. Lugar da ocorrência da heterogeneidade.

Em decorrência, discursos apontam para a diversidade entre sujeitos, seja na construção ou apropriação de sentidos. Neste caso, a lembrança da polifonia bakhtiniana nos moldes de Ducrot merece destaque, como assinala Martins:

$O$ sentido do enunciado consiste assim numa descrição da enunciação, o que quer dizer que, numa confrontação de várias vozes que se sobrepõem ou se respondem umas às outras. É verdade que o responsável pelo enunciado (o locutor) é único, e que olhadas as coisas apenas a este nível, o enunciado é um monólogo. No entanto, a m nível mais profundo, o locutor do enunciado põe em cena, no seu monólogo, um diálogo entre vozes mais elementares, a que chama enunciadores. (MARTINS, L. M: 2002, p.95).

No caso do corpus em análise, os enunciadores são sujeitos coletivos de discursos sociais que se manifestam e que só ganham existência na medida em que geram novos discursos. A temática sobre o ser humano habitante da rua demonstra haver vários discursos que necessariamente emprestam a outros normas de funcionamento, significações

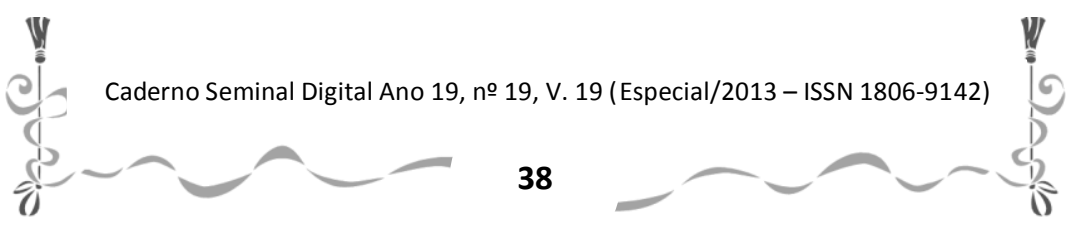


Caderno Seminal Digital

e, em termos pragmáticos, bases argumentativas para novos discursos, justamente por residir na finalidade social sua razão primeira de ser.

Cada discurso tem marcas dos sujeitos que os produzem. Sendo assim, objetividades e subjetividades estão presentes na medida em que diferentes agentes atuam como leitores e reprodutores desses discursos, mesmo sendo eles alimentados por determinações coletivas. Estamos falando de uma objetividade discursiva que passa pelo olhar subjetivo do outro sobre o sentido. Justamente pela análise semiótica visase tornar perceptível aquilo que possa estar presente no plano das intencionalidades.

Em conformidade com as intenções do estudo, procurou-se a tipificação do morador de rua. Identificar os traços de sentidos utilizados pelos discursos oficiais voltados a esse segmento social. O Discurso Jornalístico foi compreendido como o espaço do narrador do cotidiano, enunciador de cenas que revestem os acontecimentos do dia a dia em anomalias, chamando nossa atenção e motivando ou nutrindo outros discursos.

Por representar um sistema culturalmente organizado, o discurso jornalístico se torna mais eficaz na medida em que sua produção discursiva não seja constituída de sentidos únicos para fatos únicos. Para sua manutenção, é mais fácil quando os eventos, nos diferentes universos de discursos com os quais dialoga, correspondam aos tipos funcionais dos

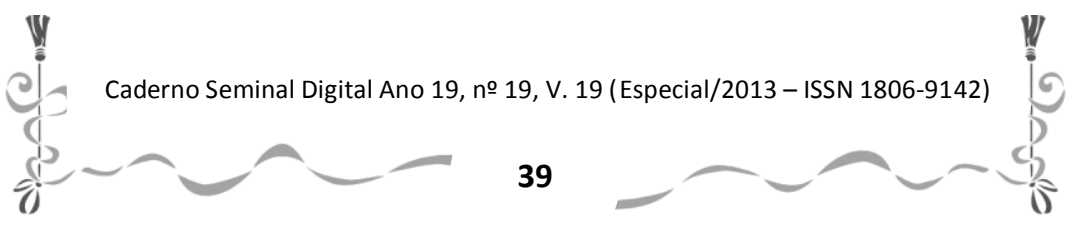


Caderno Seminal Digital

î.

modelos lógicos semânticos. A tarefa do jornalismo não é reproduzir a realidade e sim organizá-la, classificá-la e interpretá-la (VOLLI, 2007,p.257).

\section{2- DISCURSOS E SENTIDOS: NÃO INCLUSÃO E A NEGAÇÃO DO OUTRO}

O discurso jornalístico se caracteriza como o lugar do olhar que se permite ver e dialogar com os diversos sujeitos discursivos que por ele (ou nele) se manifestam, direta ou indiretamente. Definido o jornal como documento de pesquisa, o próximo passo foi definir o eixo narrativo sobre o qual se definiria a seleção de matérias. A escolha recaiu sobre matérias cuja utilização do termo moradores de rua fosse manifestada na sintaxe de superfície.

Quem são os moradores de rua no cotidiano midiático? A resposta: atores que, ao mesmo tempo que sãos sujeitos na matéria jornalística, se constituem em objetivos da perversidade de agentes de atos de violência em Brasília e em Recife. Associadas ao mês de fevereiro de 2012, na Folha de S. Paulo, edição on-line.

Em dois moradores de rua são mortos a tiros no Distrito Federal de Brasilia narra episódio sobre dois moradores mortos nos arredores de Brasília, em Taguatinga, com tiros na cabeça. Diz ainda que duas semanas antes do ocorrido, sete homens incendiaram dois mendigos em Santa Maria, outra cidade satélite de Brasília Um deles teve $63 \%$ do

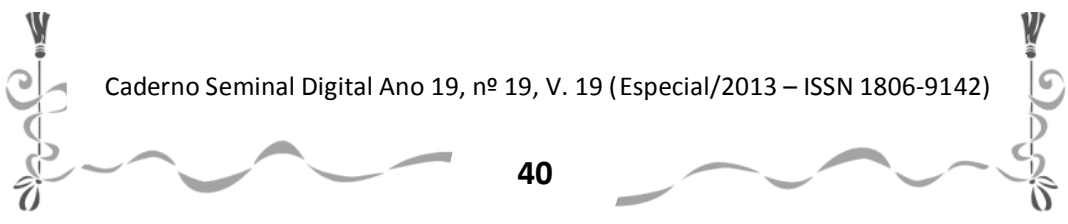


Caderno Seminal Digital

î.

corpo queimado e morreu no dia seguinte. O outro teve queimaduras em $22 \%$ do corpo e continuava internado em estado grave. Segundo o polícia, o mandante, dono de uma marcenaria, pagou $R \$ 100$ para que os demais dessem "um susto" nos moradores de rua, cuja presença prejudicava o comércio.

No episódio narrado em Morador de rua é atacado e tem $45 \%$ do corpo queimado em Recife, um morador de rua, com 31 anos de idade foi atacado por duas pessoas que atearam fogo em seu corpo, enquanto a vítima dormia. Os policiais disseram que o crime pode ter sido cometido por um casal também morador de rua. Alguém entregou para a polícia uma garrafa contendo álcool, provavelmente utilizada para a prática do crime.

A leitura inicial revela a existência de um cenário onde sobressai a violência, comum aos espaços urbanos e às periferias dos grandes centros, Sendo comum, seria apenas mais um fato entre tantos que denotam a banalização da vida humana. As duas matérias apontam para um resultado importante: morador de rua aparece no discurso jornalístico, no período estudado, como objeto da violência, marcada por dois campos distintos: violência como higienização por agentes contratados e violência entre pares.

Uma sondagem inicial sobre o eixo condutor morador de rua faz com que sejam identificados alguns marcadores lexicais: a rua como morada. "casa ou lugar onde se habita;

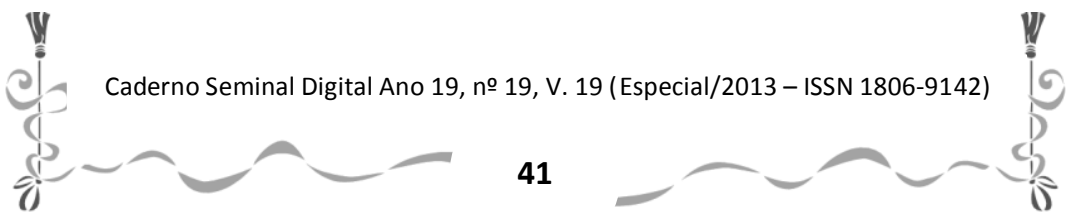


Caderno Seminal Digital

离

período em que permanece domiciliado; endereço; morador: que mora ou habita." No caso em análise, o contexto de ocorrência morador de rua reforça o sentido de haver uma categoria humana em nossa sociedade que tem como endereço a rua:

Dois moradores de rua foram mortos ontem de manhã em, cidade satélite de Brasília (1ㅇdiscurso)

Um morador de rua, de 31 anos, sofreu queimaduras após ser atacado por duas pessoas que atearam fogo no seu corpo no Recife. (2ㅇdiscurso)

O contexto de ocorrência apresenta um campo semântico que expressa uma valia em termos de sentido, um indicativo que presume em termos sociais o entendimento de que em nossa sociedade, há aqueles que tem na rua sua residência . Observa-se uma categorização, uma tipificação em termos de cidadania. Ao mesmo tempo, haver a aceitação do termo, presumida pelo uso e ocorrência, evidencia que a terminologia é compreendida e fazendo parte de muitos discursos em circulação no cotidiano, não apenas do discurso jornalístico, no eixo, portanto, da normalidade.

Aspecto diferente se observa na escrita pública onde há outra configuração semântica: população em situação de rua. Neste caso, a expressão pressupõe um número de brasileiros que está em situação de rua, sem moradia, sem residência. As ações das políticas públicas são pensadas para a eliminação de uma anomia, permitindo entender que morador

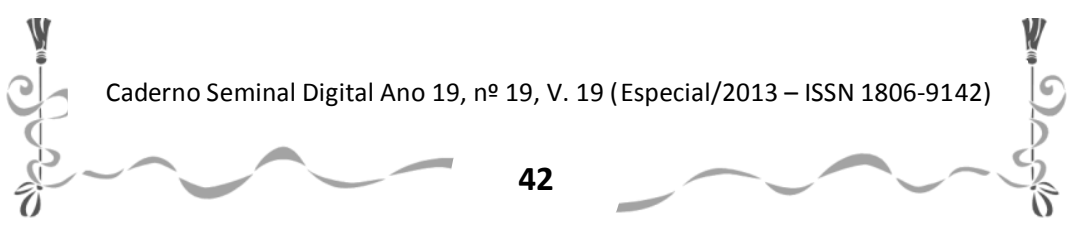


Caderno Seminal Digital

î

de rua está fora da aceitação para a vida cidadã, gerando, em decorrência, a Elaboração da Política Nacional de Inclusão Social da População em Situação de Rua, (Decreto s/no, de 25/10/2006).

Nota-se que a normalidade aprendida pelo uso da expressão morador de rua manifestada no discurso jornalístico está carregada de uma aceitação e compreensão aparente. 0 morador de rua não é nomeado, é apenas "um" indefinido morador que foi queimado, tão incômodo ao enunciador do cotidiano jornalístico como à sociedade em sua totalidade. Tão inoportuna sua existência que motiva a Política Nacional de Inclusão Social em Situação de Rua.

A contradição está assinalada na forma pela qual se busca eliminar o incômodo. Um seguimento opta pelas práticas democráticas, gerando Políticas Públicas, assumindo papéis de sujeitos capazes de engendrarem ações transformadoras para a sociedade. A escolha pelo caminho oficial é modalizada pelo poder-dever- fazer.

Por outro lado, aqueles que seguem um caminho marcado pela intolerância. Negam haver um ser humano morador de rua, queimando-o, matando-o. Além de não reconhecerem no outro a cidadania, também não se reconhecem como cidadão do Estado de Direito e democrático. O desrespeito à vida vem acompanhado pelo não respeito à sociedade. São agentes excluídos da civilização

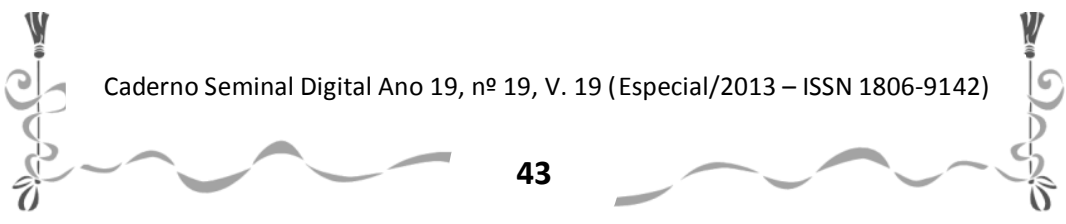


Caderno Seminal Digital

que tem suas ações marcadas pelo não poder- saber cidadania.

População em situação de rua simboliza sentidos do termo exclusão: expulsão, desenraizamento e privação. $\mathrm{Na}$ tipificação do sujeito, discurso público traz a seguinte fala:

(...) pode-se dizer que o fenômeno população em situação de rua vincula-se à estrutura da sociedade capitalista e possui uma multiplicidade de fatores de natureza imediata que o determinam. $\mathrm{Na}$ contemporaneidade, constitui uma expressão radical da questão social, localiza-se nos grandes centros urbanos, sendo que as pessoas por ele atingidas são estigmatizadas e enfrentam o preconceito como marca do grau de dignidade e valor moral atribuído pela sociedade. (Silva, 2006, p.95)

No eixo do contraditório, reconhecer essa população e sua condição de não pertencimento, que essas pessoas são estigmatizadas e enfrentam o preconceito como marca do grau de dignidade e valor moral atribuído pela sociedade, além de revelar que não é para haver pessoas sem lar, sem habitação, aceitar certa naturalidade do fenômeno. Em síntese o morador de rua é frágil, descoberto, exposto à violência nos vários traços de sentido que configuram o vocábulo.

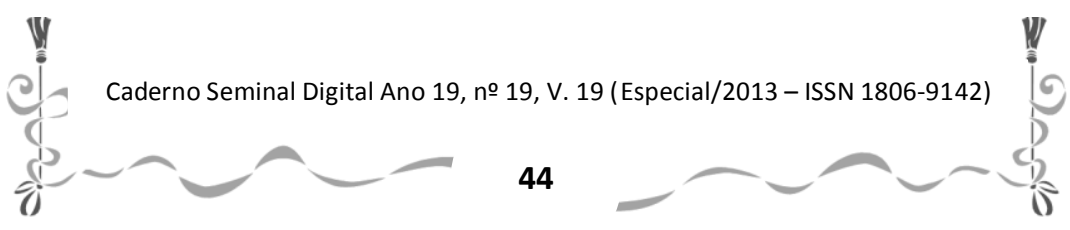


Caderno Seminal Digital

\section{3- CONSIDERAÇÕES FINAIS}

O estudo aqui apresentado faz parte de um projeto de pesquisa que tem em seus objetivos buscar elementos que permitam trazer subsídios para uma maior compreensão sobre as políticas públicas de inclusão social, principalmente aquelas destinadas às cidades e seus habitantes e que perpassam questões em torno da qualidade de vida. Quais são os valores embutidos nos processos de recepção por parte do habitante cidadão das problemáticas coletivas e dos encaminhamentos para demandas tão específicas.

No caso da população em situação de rua, ou do morador de rua, foi possível perceber que, ainda que em estudos iniciais, a violência e a axiologia ligada não podem ser compreendidas apenas dentro dos cenários urbanos da sociedade brasileira. Encontra-se a presença do habitante de rua em várias cidades do planeta. Neste caso, a situação econômica e os valores presentes nas políticas públicas produzem ações com maior ou menor eficácia para a questão.

Os fragmentos discursivos analisados revelaram a existência de um outro componente de sentido atuando como agente motivador: o medo. A sociedade contemporânea busca a semelhança e tem medo do diferente. Tolerância é palavra chamada para o cotidiano pela necessidade de aceitação das diferentes de gênero, religião, regionais, preferências esportivas e nacionalidade.

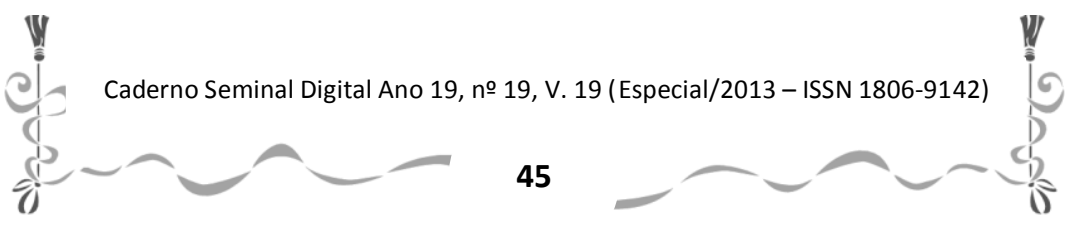


A população em condição de rua elabora sua memória de vida em trânsito. Mora onde todos transitam, ilhada no movimento que joga o não ser, não pertencer. Marca da não limpeza social, prova das diferenças e injustiças sociais e dos roteiros do consumo. Em oposição, homens formados pela sociedade do consumo, da aparência, das necessidades da posse dos objetos materiais na constituição de identidades.

Os moradores dos grandes condomínios espalhados pelas cidades buscam o distanciamento do que lhe representa o medo da perda da posse, das marcas da violência, da feiura da pobreza. O medo do outro, o medo de perder sua condição social, o medo motivado pelo estranhamento do outro que faz romper a identidade como o humano que mora na rua.

A rua assinala o contexto de ocorrência de um discurso de poder na medida em que as políticas públicas são realizadas com base em valores democráticos, negados, por princípio, pelos estes sujeitos que assumem um discurso de poder não verbalizado. Para eles o espaço da rua é de circulação da higiene dos signos e símbolos de consumo. Com em um ritual, queimam o humano não visível.

Bauman (2009) aborda a questão do medo do estranho na sociedade contemporânea contrapondo a modernidade sólida à modernidade líquida. Esta última, ao retirar a ideia de permanência e revelar a não estabilidade das relações de trabalho e da posse do capital, fortalece o individualismo e a

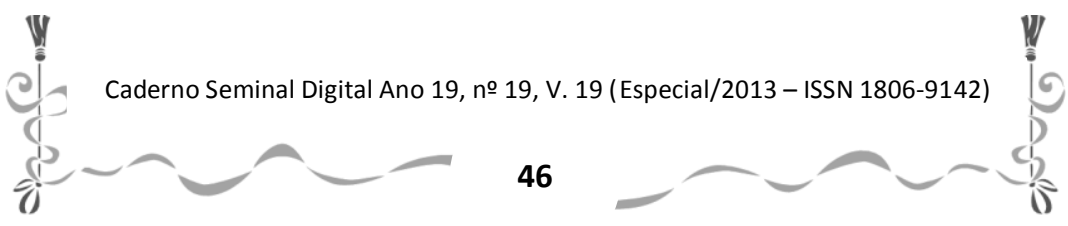


Caderno Seminal Digital

defesa do que Ihe é local. A solidariedade é trocada pela competição e os indivíduos manifestam um sentimento de abandono,

Talvez seja possível entender as ações de violência aqui apresentadas como parte de um sentimento de negação do estranho. De certa forma, os aspectos dinâmico e estático implícitos em situação e morador de rua evidenciam que nossa sociedade tem como valor a melhora de qualidade de vida para todos e que a violência não é um bem coletivo.

\section{REFERÊNCIAS BIBLIOGRÁFICAS}

BARBOSA, M. P. Língua e Discurso: contribuição aos estudos semânticos-sintáticos. São Paulo: GLOBAL, 1978.

BAUMAN, Z. Confiança e Medo na Cidade. Rio de Janeiro; ZAHAR,2009.

FOUCAULT, M. Arqueologia das Ciências e História dos Sistemas de Pensamento. Trad. Elisa Monteiro. São Paulo: Forense Universitária, 2000.

FEDERAL. Política Para Inclusão da População em Situação de Rua. Brasília, Ministério do Desenvolvimento Social e Combate a Fome. Disponível em: http://www.mds.gov.br

MARTINS, Moisés L. A linguagem, A Verdade e o Poder. Ensaio de Semiótica Social. Coimbra: Fundação CALOUSTE GULBENKIAN /MISTÉRIO DA CIÊNCIA E FONSECA, J. Heterogeneidade na Língua e no Discurso. Disponível em: http://ler.letras.up.pt/uploads/ficheiros/2626.pdf

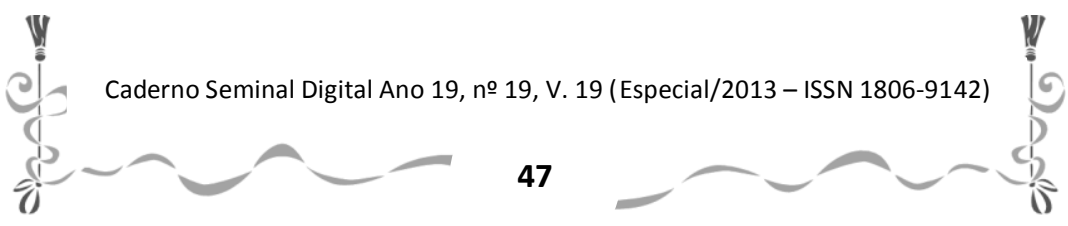


MELO, E. M; PRADOS, Rosália M. Netto; GARCIA, Wilton. Linguagens, Tecnologias e Culturas: discursos contemporâneos. São Paulo: Factash Editora, 2008.

SECCHI, Leonardo. Políticas Públicas. Conceitos, Esquemas de Análise, Casos Práticos. São Paulo: CENGAGE Lerning, 2010.

SILVA, Maria Lopes. Mudanças recentes no mundo do trabalho e o fenômeno de População de Rua no Brasil - 1995-2005-2006. Dissertação Mestrado. Universidade de Brasília - Disponível em: http://WWW.bce.unb.br/

VOLLI, U. Manual de semiótica. Trad. Silvia Debetto. São Paulo: Edições Loyola, 2007.

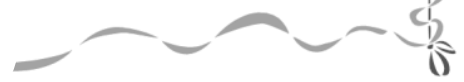

